CALIFORNIA INSTITUTE OF TECHNOLOGY

Division of the Humanities and Social Sciences Pasadena, California 91125

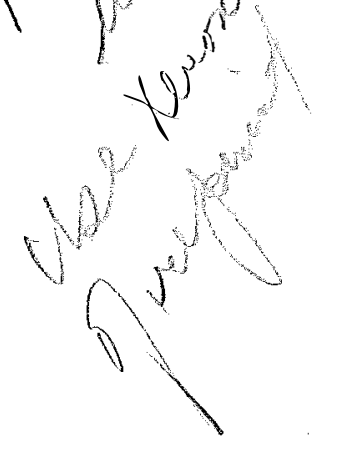

VOTERS, BUREAUCRATS AND LEGISLATORS:

A RATIONAL CHOICE PERSPECTIVE ON THE GROWTH OF BUREAUCRACY

Morris P. Fiorina and Roger G. No11

Presented at the INTERNATIONAL SEMINAR ON PUBLIC ECONOMICS Namur, Belgium

November 26-28, 1976

To be published in the Journal of Public Economics.

Social Science Working Paper

Number 159

Apri1 1977

(revised June 1977)
VOTERS, BUREAUCRATS AND LEGISLATORS:

A RATIONAL CHOICE PERSPECTIVE ON THE GROWTH OF BUREAUCRACY

by Morris P. Fiorina and Roger G. No $11^{*}$

ABSTRACT

The claim that government is excessively bureaucratic can be interpreted as an assertion about inefficient factor proportions in the production of public goods. The rational choice theory of electoral competition is extended in this paper to include the election of representatives from separate districts, ombudsman activities by legislators, self-interested bureaucrats and production functions for public activities that have bureaucratic and nonbureaucratic arguments. If the demand for public goods grows exogenously through time, the mode1 predicts increasingly inefficient factor proportions yet a growing advantage for incumbent legislators when they seek reelection.

* California Institute of Technology.

The authors gratefully acknowledge the comments and suggestions on an earlier draft from James Buchanan, Bruce Cain, John Jackson, Julius Margolis, Alan Peacock, Sam Peltzman, Barry Weingast; and an anonymous referee. 
A common criticism of the modern state is that it has become excessively bureaucratized. Agencies which provide public goods and services supposedy entangle citizens in red tape, thereby imposing significant costs on individuals and businesses. Yet despite this criticism, democracies the world over continue to legislate new bureaucracies and to expand old ones.

The obvious question suggested by this state of affairs is how excessive bureaucracy can arise and persist in a democracy despite its apparent unpopularity. In principle, several explanations are available. One is that democratic government may be a charade; the welfare of citizens may bear no consistent relation to the policies pursued by government, even in the long run. Another is that bureaucratization of public organizations may be the most efficient mechanism for providing public goods and services. Complaints about bureaucracy may be akin to discontent about the impossibility of a free lunch.

A third possibility is examined in this paper: some government institutions create incentives which lead self-interested, rational individuals to behave in a manner that causes excessively bureaucratized government. This hypothesis is examined here within the contexts of a simple economic model of utility-maximizing voters, vote-maximizing politicians and bureaucracy-maximizing agencies. The model incorporates in a rudimentary fashion the effects of several common (but not universa1) governmental institutions: One is the practice of dividing the electorate into separate constituencies, each of which is represented in the legislative body by one legislator. Another is a system of taxation in which citizens pay taxes that are not based solely on the value they place on government activity. A third is a political system in which the bureaucracy is separate from the legislature and members of the legislative body both act as legislators and as ombudsmen for constituents who become ensnared in the bureaucracy. A fourth is a governmental structure in which senfority and government experience affect the ability of a legislator to perform the ombudsman role. In sum, the model depicts a society that is governed by an autonomous, decentralized, unicameral legislature, the members of which are elected by plurality vote in districts with a single representative. This hypothetical institution is patterned after the U.S. House of Representatives or the French House of Deputies, although the model does not incorporate the strong, independent executive that is present in these countries.

The principal conclusion derived from the model is that a11 of the institutions included in the model contribute to excessive bureaucratization, even if agencies do not seek to maximize societal expenditures on bureaucratic institutions. Obviously, the latter behavior can exacerbate the problem. 


\section{A CONCEPTUAL FRAMEWORK}

The analysis that follows is based upon the assumption that a production function for a government activity is a theoretically and empirically meaningful concept and, moreover, that the arguments of such a function are separable into those that constitute the bureaucratic aspects of the activity of an agency and those that represent resources used in the physical provision of the government good. This assumption is controversial. 01son (1973) argues that government activities production efficiency cannot be accurately measured, and Wildavsky (1974) contends that agencies use natura1 informational advantages in dealing with the legislature on budgetary issues. Nevertheless, the assumption will be maintained since without it, one cannot address the question of whether governmental organizations are excessively bureaucratized.

Bureaucratization within an organization can contribute to economic efficiency if it allows an organization to realize the economies of division of labor while retaining a common organizational objective among employees. Weber (1946) characterizes the principles that underlie modern public bureaus as: (1) Hire and promote.employees on the basis of performance; (2) Assign employees clear duties and responsibilities; (3) Keep formal records of the activities of each member of the organization; and (4) Arrange the organization hierarchically, branched according to organizational functions and vertically segmented according to the degree and breadth of managerial responsibility, in order to facilitate communication, personnel assessment, and unambiguous assignment of responsibility for each activity of the organization and for its overa11 performance.

Associated with these principles are potential problems. Clients of the organization may not know who has responsibility for the particular problems that they face. Or, instructions to an employee regarding duties and responsibilities may not cover the particular problem of a client. As a result, the employee may respond ineffectively to a demand for services.

Bureaucratic costs consist of the time and resources expended to overcome these problems. Some bureaucratic costs are Internal to the bureaucracy, such as the costs of collecting, storing and analyzing data about the work activities of employees, and of communicating and enforcing organizational policies from the highest managerial personnel to lower-level employees. Other bureaucratic costs are born by the clients of the organization, such as the costs associated with discovering the appropriate entry point to the bureaucracy and providing the information the bureaucracy requires for its own internal maintenance purposes. Bureaucracy is excessive if it exceeds the amount that, combined with the other expenses of the organization, minimizes the total costs (including costs born by clients) of providing a given amount of services.

In the theoretical mode1 to follow, the legislature performs several functions. It selects the amount of public goods that will be provided and the technology that will be used to produce public goods. In addition, the members of the legislature 
assist citizens in dealing with the bureaucracy. The oversight function of the legislature gives it influence with bureaucrats and information on how the bureaucracy works, both of which are potentially of value to citizens who come in contact with the agency. If Finally, the legislature selects the taxation system

1/ The argument in this paper abstracts from the possibility that the legislature may adopt a committee structure to divide responsibility for acquiring various types of public goods. While the committee system is potentially of great importance, reciprocity rules vitiate its significance for the particular purposes of this paper (see Weingast (1976)).

that will be used to finance government activity.

A key feature of legislative bodies is the difference between the legislator's roles as a facilitator and as a participant in formulating public policies. In deciding on taxation, expenditures, the technology of the public sector, and general public policy, the legislature is a majority rule institution. Consequent1y, a legislator is not 1ikely to have much of an impact on legislative outcomes. On the other hand, if legislators are elected by district, each legislator will be one of few potential sources of facilitating services. Indeed, in a unicameral system with district representation, each legislator is a local monopolist in supplying these services. Moreover, in providing bureaucratic unsticking services, the legislator acts independently, rather than by acquiring majority support among other legislators.
Consequent1y, a legislator is fully accountable to the voter for facilitation services, but not fully responsible for the policy outcomes of the legislature. The result is a prisoner's dilemna outcome for voters.

\section{THE FORMAL MODEL}

Economic mode1s of voting behavior hypothesize that citizens decide which candidate to support by comparing the personal benefits that they expect to recelve as a result of the election of each of the opposing candidates. Citizens are assumed to integrate decisions about political and economic activities in selecting a most preferred combination of consumer goods and public policies from among the avallable alternatives. In the model to follow, the ordering of these alternatives is represented by a utility function over two commodities (one private, one pub1ic) for each consumer, written as:

$$
\mathrm{U}^{\mathrm{ij}}\left(\mathrm{z}_{i j}, \mathrm{~K} \mid \mathrm{K}_{\mathrm{j}}\right)
$$

where $(i, j)$ is an index.over all citizens, representing the $i^{\text {th }}$ consumer in the $j^{\text {th }}$ constituency $(i=1, n$ and $j=1, m), z_{i f}$ is the consumption of the private good by $(1, j), K_{j}$ is the amount of the public good proposed by the legislator of constituency j, and $\mathrm{K}$ is the amount of the public good that will be acquired, given the positions, $\mathrm{K}_{\mathrm{j}}$, of all of the legislators that will be elected. For purposes of this analysis, the essential feature of $K$ is that government provides it outside of the market system, not that it 
is of necessity collectively consumed. It is assumed that $U_{2}^{1 j}>0$ and $U_{K}^{1 j}>0$, and that $z_{1 j}$ and $K$ are continously variable and nonnegative.

Each consumer has positive income $y_{1 j}$ to be allocated among purchases of the private good, taxation $\left(t_{1 j}\right)$ that is used. for acquiring the ptblic good and providing facilitation services, and the expense of dealing with the government bureaucracy.

Letting all other prices be relative to the price of the private good, the budget of a citizen is represented as:

$$
y_{i j}=z_{1 j}+t_{1 j}+C\left(B, F_{1 j}, I_{j}^{b}\right) \text {, }
$$

where $C$ represents the external costs to $(i, j)$ of a bureaucracy of size $B$, given facilitation services in the amount $F_{1 j}$ by the citizen's legislator who has bureaucratic influence $\mathrm{I}_{j}^{\mathrm{b}}$. The influence of a legislator in providing effective facilitation services is affected by the party identification, seniority and experience of the legislator, so that for each candidate it is a parameter rather than a variable under the candidate's control. The shape of the bureaucratic cost function is assumed to exhibit a positive and rising marginal cost of bureaucracy, e.g. $C_{B}>0$ and $C_{B B}>0$, and a positive but falling marginal benefit of facilitation, or $\mathrm{C}_{\mathrm{F}}<0$ and $\mathrm{C}_{\mathrm{FF}}>0$. An increment of $\mathrm{F}$ is assumed to reduce marginal bureaucratic costs, e.g. $\mathrm{C}_{\mathrm{BF}}<0$. Influence is assumed to reduce bureaucratic costs as we11, but with falling marginal effect, and to make facilitating services more effective. Hence, $\mathrm{C}_{\mathrm{I}}<0, \mathrm{C}_{\mathrm{II}}>0, \mathrm{C}_{\mathrm{BI}}<0$, and $\mathrm{C}_{\mathrm{FI}}<0$.
Total tax collections from all citizens must exactly match a11 government expenditures:

$$
\sum_{i, j} \cdot t_{1 j}=P_{b} B+P_{x} X+P_{f} \sum_{1, j} F_{1 j},
$$

where $B$ and $X$ represent the amount of bureaucratic and other inputs, respectively, to the provision of the public good, and $\mathrm{P}_{\mathrm{b}}, \mathrm{P}_{\boldsymbol{X}}$ and $P_{f}$ are the relative costs of $B, X$ and $F_{1 j} \cdot$ Finally, the transformation of inputs $B$ and $X$ into output of the public good is written as a production function:

$$
\mathrm{K}=\mathrm{f}(\mathrm{B}, \mathrm{X}),
$$

which has the properties that more input yields more output (e.g. $f_{B}>0$ and $\left.f_{X}>0\right)$, and that the law of diminishing returns is satisfied (e.g. $\mathrm{f}_{\mathrm{BB}}<0$ and $\mathrm{f}_{\mathrm{XX}}<0$ ).

\section{Socia1 Welfare Maximization}

Assuming that society seeks to maximize the sum of Individual utility functions, a philosopher-king would solve the following constrained maximization problem:

$$
\begin{aligned}
& \text { Maximize: } \sum_{i, j} U^{1 j}\left(z_{i j}, K\right) \\
& \text { Subject to: } K=f(B, X) \\
& \qquad \sum_{i, j} y_{i j}=z_{i j}+\sum_{i, j} C\left(B, F_{i j}, I_{j}^{b}\right)+P_{f} \sum_{i, j}^{r} F_{i j}+P_{b} B+P_{x} X
\end{aligned}
$$

With $\gamma$ and $\lambda$ adjoined to these constraints as Lagrange multipliers, the first-order conditions for a maximum are: 


$$
\begin{array}{ll}
\sum_{i, j} U_{K}^{i j}+\gamma=0 & \\
U_{z}^{1 j}-\lambda=0 & \text { for all } 1, j \\
-\lambda\left(\sum_{i} C_{I}\left(B, F_{i j}, I_{j}^{b}\right)\right)=0 & \text { for all } j \\
-\lambda\left(\sum_{i, j}^{\left.C_{B}\left(B, F_{i j}, I_{j}^{b}\right)+P_{b}\right)-\gamma f_{B}(B, X)=0}\right. & \\
-\lambda P_{x}-\gamma f_{X}(B, X)=0 & \\
-\lambda\left(C_{F}\left(B, F_{i j}, I_{j}^{b}\right)+P_{f}\right)=0 & \text { for all } 1, j
\end{array}
$$

The first two equations are the familiar conditions of consumption efficiency. When combined, and using (4) or (5) to interpret the ratio of the Lagrange multipliers, (1) and (2) require that the ratio of the effect on total welfare of an increment of the public good to the value to a particular citizen of an increment of the private good equals the ratio of the costs of those increments. Equation (3), assuming that the income constraint is binding (so $\lambda \neq 0$ ) and that the costs of bureaucracy are positive, reduces to a requirement that legislator influence on the bureaucracy be sufficiently great that no further increase in influence can reduce bureaucratic costs $\left(\mathrm{e}, \mathrm{g}, \mathrm{C}_{\mathrm{I}}=0\right)$. This result arises from the absence of a cost of increased influence in the structure of the model. Since influence is a parameter to the legislators, this condition is best interpreted as indicating the optimality of professional legislators of the controlling party, assuming that such a condition is consistent with the optimal choice of $K$ and the tax rule. In any event, some influence, even if it were costly to create, would emerge from this type of model since informational facilitation services in a complex bureau can, in principle at least, reduce total societal costs arising from public goods.

$$
\text { Equations (4) and (5) together yield the condition for }
$$
production efficiency of the public good, namely that the ratio of the marginal productivities of the two inputs equal the ratio of their social costs. The social cost of $x$ is merely its price; however, the social cost of $B$ includes external costs:

$$
\frac{f_{B}(B, X)}{f_{X}(B, X)}=\frac{P_{b}+\sum_{i, j} C_{B}\left(B, F_{i j}, I_{j}^{b}\right)}{P_{x}}
$$

Condition (6), assuming $\lambda \neq 0$, provides a condition for efficient use of facilitation services. Rearranging the term in parentheses, the condition becomes:

$$
\mathrm{C}_{\mathrm{F}}\left(\mathrm{B}, \mathrm{F}_{i j}, \mathrm{I}_{\mathrm{j}}^{\mathrm{b}}\right)=-\mathrm{P}_{\mathrm{f}}
$$

or that each citizen should acquire facilitation services up to the point at which the cost of the last increment equals its contribution to reducing private bureaucratic costs.

$$
\text { Total differentiation of (6), with } I_{j}^{b} \text { assumed }
$$

constrained with cancellation and rearrangement, yields:

$$
\frac{d B}{d F_{i j}}=-\frac{C_{F F}\left(B, F_{i j}, I_{j}^{b}\right)}{C_{B F}^{i j}\left(B ; F_{i j}, I_{j}^{b}\right)}
$$


Since in the ratio on the right side of (9) $\mathrm{C}_{\mathrm{BF}}$ and the ratio itself are negative, the left-hand side must be positive. Thus, a change in conditions that causes an increase in $F_{1 j}$ will lead to more bureaucracy. This can happen through substitution of $B$ for $\mathrm{X}$, holding $\mathrm{K}$ constant, and through increased production of $\mathrm{K}$. Letting $d B^{*}$ represent the substitution term,

$$
d B=d B *+\frac{\partial B}{\partial K} d K
$$

which, when substituted into (9) and rearranged, provides:

$$
\frac{d F_{i j}}{d K}=-\frac{C_{B F}\left(B, F_{i j}, I_{j}^{b}\right)}{f_{B}(B, X) C_{F F}\left(B, F_{i j}, I_{j}^{b}\right)}-\frac{C_{B F}\left(B, F_{i j}, I_{j}^{b}\right)}{C_{F F}^{i j}\left(B, F_{i j}, I_{j}^{b}\right)}\left(\frac{d B *}{d K}\right)
$$

The sign of the relation between $F$ and $K$, then, is positive unless the substitution of $\mathrm{B}$ for $\mathrm{X}$ declines as $\mathrm{K}$ increases, and does so by an amount sufficient to offset the first term on the right side of (11). In general, the sign of $\frac{d F}{d K}$ depends on the shape of the production function for $K$, but growing $K$ will lead to increased facilitation services unless, at higher $K$, the optimal amount of

$B$ is actually less than at lower amounts. This can be seen by observing that, because $\frac{d B}{d F}$ is positive, $\frac{d F}{d K}$ can be negative only if $\frac{d B}{d K}$ is negative, which, from (10), requires that $\frac{d B^{*}}{d K}<-\frac{\partial B}{\partial K}=-\frac{1}{f}$. Since this case is implausible, if an external factor such as growth in income or technical progress in producing $K$ causes an increase in the quantity of $K$ produced so, too, will it cause increasing bureaucracy and facilitation services. Growing bureaucracy and increasing provision of facilitation services, then, can be expected in a growing economy, even if it operates efficiently.

\section{Decentralized Decisions}

For the purposes of this paper, a decentralized system refers to a society in which competitive markets allocate private goods and productive resources, and majority-rule elections, in which all citizens receive a vote, select legislators. Candidates for the legislature compete for office by offering voters positions on public issues -- in this case, the amount of public good to be acquired and how it will be produced -- and an amount of facilitation services. The effectiveness of the candidate in carrying out promises of either type depends in part on the candidate's tenure in office.

Each voter/consumer decides which candidate to vote for by examining the welfare implications of competing platforms and selecting the one promising the voter the greatest individual welfare. With a probability $\mathrm{p}_{j}^{\mathrm{k}}$, a voter's legislator will be the deciding vote (median legislator) in the legislature, in which case the maximization problem faced by the voter is:

$$
\begin{aligned}
& \text { Maximize: } \quad u^{i j}\left(z_{i j}, K_{j}\right) \\
& \text { Subject to: } \quad K_{j}=f(B, x) \\
& y_{i j}=z_{i j}+c\left(B, F_{i j}, I_{j}^{b}\right)+t_{i j} .
\end{aligned}
$$

With probability $\left(1-p_{j}^{k}\right)$, the voter will face the same maximization problem except that $K, B$ and $X$ will be beyond the influence of the legislator and, therefore, the voter. As long as $p_{j}^{k}$ is positive, 
and $F_{i j}$ and $z_{i j}$ are selected after $K$ is determined, the likelihood that a voter will prefer a particular candidate will increase as $\mathrm{K}_{\mathrm{J}}$ moves closer to the most preferred value. This is assured as long as candidates offer two contingent values of $F_{i j}$, one in case $K$ is supplied, the other should $K_{j}$ be selected.

According to the rational choice theory of elections, if citizen $(i, j)$ is the swing vote (median voter) in the constituency and if no candidate possesses an intrinsic advantage in influence, owing to incumbency or party identification, the equilibrium outcome of a competitive election will be the solution to the constrained utility maximization problem in which all variables are in control of the median voter $(i, j)$ in the constituency of the median legislator. $\underline{2}$ /

2/ The analysis in this section presumes familiarity with the theoretical literature on electoral competition with votemaximizing politicians and rational voters. See, for example, Buchanan and Tullock (1962); Davis, Hinich and Ordeshook (1970) and Downs (1957).

The contingent event that gives the median voter contro1 over $K, B$ and $X$ can produce no worse an outcome than if these variables are fixed; hence, all other things being equal, the median voter will prefer values of $k_{j}$ that are closer to the optimal value. Consequently, the equilibrium campaign strategy for a candidate is to offer median voter $(i, j)$ an optimal value for $k_{j}$.
To complete the model, the nature of taxation must be specified. Taxes are assumed to be based on principles that make them not wholly efficient and incentive compatible in the sense of Groves and Ledyard (1976). For the sake of simplicity, each citizen is assumed to pay an equal share in the cost of government; however, the qualitative results of the following analysis depend only on the fact that facilitation services by legislators are not purchased as used, but instead are financed from general tax revenues. Thus, one of the two utility-maximization problems that are solved for the median voter becomes:

$$
\begin{aligned}
& \text { Maximize: } \quad U^{i j}\left(z_{i j}, K_{j}\right) \\
& \text { Subject to: } \quad K_{j}=f(B, X) \\
& y_{i j}=z_{i j}+C\left(B, F_{i j}, I_{j}^{b}\right)+\frac{1}{n m}\left(P_{x} X+P_{b} B+P_{f} \sum_{i, j} \cdot F_{i j}\right) .
\end{aligned}
$$

The first-order conditions for a solution to this problem are:

$$
\begin{aligned}
& U_{K}^{i j}+\gamma=0: \\
& U_{z}^{i j}-\lambda=0 . \\
& -\lambda\left(C_{B}\left(B, F_{i j}, I_{j}^{b}\right)+\frac{P_{b}}{n m}\right)-\gamma f_{B}=0 . \\
& -\lambda \frac{x}{n \pi a}-\gamma f_{X}=0 . \\
& -\lambda\left(C_{F}\left(B, F_{i j}, I_{j}^{b}\right)+\frac{P_{f}}{n m}\right)=0 . \\
& -\lambda C_{I}\left(B, F_{i j}, I_{j}^{b}\right)=0 .
\end{aligned}
$$


The second maximization problem is the same as the first, except $K, B$ and $X$ are fixed. The first-order conditions for this problem are equations (13), (16) and (17). The solutions, of course, differ in the two problems because the values of $K, B$ and $X$ are different in these three equations.

If income constrains utility maximization, condition (17) requires that the elected candidate have maximal influence with the bureaucracy as long as bureaucratic costs are positive. If incumbency and membership in the majority party affect influence with the bureaucracies, only a candidate possessing these characteristics can offer voters an optimum platform. Furthermore, an optimum platform must obtain only under the assumption that enough candidates possessing these characteristics are in the race to assure that the voter can pick the optimal value for the other variables as we11.

Condition (16) can be rearranged, again assuming $\lambda \neq 0$, to provide the following requirement with respect to $F_{1 j}$ :

$$
C_{F}\left(B, F_{i j}, I_{j}^{b}\right)=-\frac{P_{f}}{n m}
$$

This differs from the welfare-maximizing condition in (8) by the term $\mathrm{nm}$ on the right side of the equation. The result is a weliknown consequence of "externalizing the internality" by financing a private good (here facilitation services) from a general tax. Given the conditions on $C_{F}$ and $C_{F F}$, a decentralized system results in more extensive use of facilitating services than is optimally efficient. The magnitude of the inefficiency depends upon differences between the systems in the amount of $B$ that is used in producing public goods.

Conditions (14) and (15) provide the equilibrium factor proportions when $K$ is in control of the voter, yielding:

$$
\frac{f_{B}}{f_{X}}=\frac{P_{b}+C_{B}\left(B, F_{i j}, r_{j}^{b}\right) n m}{P_{x}}
$$

Expression (7), establishing the welfare-maximizing condition, differs from (19) in that the second term of the numerator of the right-hand side of (19) has been multiplied by $\mathrm{nm}$, the number of citizens, whereas in (7) it is the sum of the private bureaucratic costs over all citizens. While this can introduce distortions, they are created by the taxation system, which affects choices of $B$ and $X$ differentially because not all of the costs of $B$ are pafd by the government out of tax revenues. The direction of the distortion depends upon whether the median voter faces bureaucratic costs that are higher or lower than average.

Combining the inference drawn from (18) with (19) produces another distortion that always works to produce excessive bureaucracy. Since $F_{1 j}$ exceeds the optimal value, the function $C$ takes on a value that is closer to zero than is optimal. At the equilibrium value for $B$ in the welfare-maximizing problem, (19) would not be an equality since the right-hand side would be too small. Equality could be restored by increasing $B$ by producing more $K$ and substituting $B$ for $X$, with the distribution between these two actions dependent on the shapes of the production and bureaucratic cost functions. 
Conditions (12) and (13) provide the equilibrium conditions for the relative consumption of public and private goods when the voter controls $K$. Since, from (14) or (15), $-\gamma / \gamma_{\lambda}$ is the marginal cost of public goods and by hypothesis unity is the marginal cost of private goods, (12) and (13) together require that the ratio of marginal utilities be equal to the ratio of marginal costs. Since excessive use of facilitation services lowers the private costs of bureaucracy, the resulting equilibrium involves excessive consumption of public goods.

If incumbency or party membership are permitted to affect the influence of a candidate in providing facilitation services, the competitive equilibrium value of $k_{j}$ will not necessarily be proposed by any candidate. An incumbency or party advantage with regard to influence enters the model in the following ways. If $I_{j 1}^{b}$ exceeds $I_{j 2}^{b}$ and candidate 1 matches candidate 2 on a11 other variables $\left(K, B, X\right.$ and $\left.F_{1 j}\right)$, the first makes the welfare of $(i, j)$ higher because candidate 1 will have reduced the expenditures of $(1, j)$ by the amount $C\left(B, F_{i j}, I_{j 2}^{b}\right)-C\left(B, F_{i j}, I_{j 1}^{b}\right)$ whether $K$ is or is not controlied by $(i, j)$. Candidate 1 can then adjust positions on the public issues away from the median voter's optimum values and still capture the election as long as the reductions in welfare so induced do not offset the reductions in bureaucratic costs that are made possible by the candidate's greater influence. The smaller is $\mathrm{p}_{j}^{\mathrm{k}}$ for all candidates, the smaller is the expected cost of a suboptimal $\mathrm{K}_{\mathrm{f}}$ and hence the greater is the extent to which the value of $k_{j}$ proposed by candidate 1 can diverge from the optimum and still not offset the effects of differences in $I_{j}^{b}$. of course, the optimum values of $\mathrm{K}_{j}$ and $\mathrm{F}_{i j}$ for the median voter are not the same for both candidates. For any given $K_{j}, F_{1 j}, B$ and $X$, the price of $K_{j}$ is lower if an incumbent is elected than if the challenger wins since the former offers more effective facilitation services. Equations (12), (13) and (14), when combined, yield:

$$
\frac{U_{Z}^{i j}}{U_{K}^{1 j}}=\frac{f_{B}}{c_{B}\left(B, F_{1 j}, I_{j}^{b}\right)+\frac{P_{b}}{n m}} .
$$

Since $C_{B I}<0$, at equilibrium values of $B, X$ and $F_{i f}$ for the challenger $C_{B}$ would be too small to be an equilibrium for the incumbent. Similarly, in equation (18), $\mathrm{C}_{\mathrm{F}}$ is too small to be an equilibrium. To restore equilibrium for the median voter requires some combination of increasing $B$, which is achieved by increasing $\mathrm{K}$ and by substituting $\mathrm{B}$ for $\mathrm{X}$, and increasing $\mathrm{F}_{1 \mathrm{f}}$ since $\mathrm{C}_{\mathrm{FF}}>0$. The implications of these results are several. First, incumbents who perform well as facilitators should defeat challengers unless they offer outlandish positions on public policies. Second, incumbents should have a greater reelection advantage as government activity grows, assuming that $C_{I B}<0$. Third, because facilitation is financed from general tax revenues, voters use too much of 1 t. Consequently, the equilibrium amount of public acțivity for a candidate to offer is too great, and the advantage of incumbents in elections is larger than it would be if facilitation were appropriately priced. 
If the legislature can structure itself and the bureaucracy so that incumbency becomes more important, it has an incentive to do so. The greater is the effect of incumbency on influence, the greater is the advantage of the incumbent in reducing bureaucratic costs and maximizing expected utility in comparison with the platform of a challenger in the next election. By analogous reasoning, if a majority party can increase the extent to which membership in that party determines influence, it has an incentive to do so.

\section{Bureau-Maximizing Agenctes}

The preceding sections presume that agencies are passive conduits for decisions by the legislature on the amount of public goods to be produced and the factor proportions to be used in producing them. Here this assumption is replaced by the hypothesis that agencies seek to maximize bureaucratic inputs to the production of public goods rather than total expenditures, as assumed by Niskanen (1971). For example, an agency which provides transfer payments might seek to increase contact between caseworkers and clients or the total caseload because both lead to greater Bureaucratic input, while being less enthusiastic about proposals to provide across the board increases in payments.

The structure of the civil service as described by Warner, et al (1963) provides the rationale for this model. Unlike market-oriented private organizations, neither government organizations nor the people who populate their hierarchies have much opportunity for entrepreneurial gains. The main exception is that the number of civil service jobs at high grades, and the prestige and perquisites of politically appointed positions, depend in part upon the number of employees in the agency. A career employee can increase the chance for promotion to the highest civil service grades, and a political appointee can increase the desirability of the job of agency head, by working to expand the size of the agency. This is done by increasing the amount of bureaucracy associated with existing programs and increasing the number and leve1 of support of programs.

Formally, the agency is seen as solving the following problem:

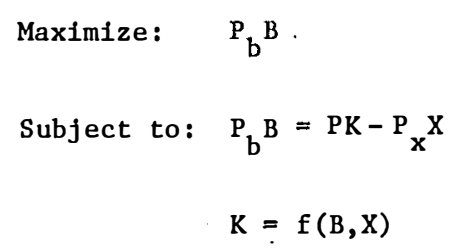

The first-order conditions are:

$$
\begin{aligned}
P_{b}-\lambda P_{b}+\gamma f_{B} & =0 \\
-\lambda P_{X}+\gamma f_{X} & =0 \\
\lambda\left(P-\frac{d P}{d K} K\right)-\gamma & =0
\end{aligned}
$$

Equation (22) permits analysis of the differences between monopolistic and competitive bureaus, depending on whether $\frac{\mathrm{dP}}{\mathrm{dK}}$ is assumed to be negative or zero. The second-order conditions require that both $\lambda$ and $\gamma$ be positive; hence, a monopoly bureau will operate on the elastic portion of its demand curve. Furthermore, 
bureaucratization (perhaps unmeasurable), which in turn will lead to greater success in seeking reelection by incumbents and greater devotion of legislators to facilitation services.

No definitive empirical test of these propositions is offered here. To do so would require a sophisticated statistical analysis of the relationship between the electoral success of incumbents and numerous other factors, including the size of the bureaucracy and the devotion of the incumbent to constituent services. Still, rough trends in the United States indicate that a more detailed empirical investigation of the theoretical arguments advanced In this paper is warranted.

In the past few years, incumbents have enjoyed a growing advantage in American congressional elections. 4/ In 1976, on1y

4/ On the incumbency effect, see Erikson (1971); Mayhew (1974); Tufte (1972); Burnham (1964) and especially Ferejohn (1977) who succeeds in dismissing the conventional explanations for the phenomenon.

thirteen of the 385 members of the U.S. House of Representatives who sought reelection were defeated, and, including retirements, about 14 percent of the Congress turned over. A century ago, turnover rates were normally in the range of 40-50 percent, and occasionally were much higher (73 percent in 1842,61 percent in 1852). Since the late nineteenth century the involuntary turnover rate has sharply declined. The most recent decline occurred in the late 1960s, following the implementation of the Great Society programs and despite the enactment of a very generous congressional retirement program that led to an increase in voluntary retirements of senior congressmen.

The congressional resources devoted to constituency services can be crudely measured by analyzing the records that Congress keeps with regard to the activities of representatives and their staffs. As Fiorina (1977) shows, these data reveal substantial increases in facilitation activities. For example, one measure of resources devoted to constituency service is the assignment of staff to district offices, where the principal activity is receiving complaints from constituents, rather than to the Washington, D.C. office, where legislative and other policy matters are dealt with. Between 1960 and 1974, the number of staff workers operating in district offices rose from fewer than one per district in 1960 to about four per district in 1974.

5/ Fiorina (1977), pp. 56-60.

Even if more refined empirical studies of the United States support the theory presented in this paper, other questions about the importance of the model remain. Growth in bureaucracy apparently is ubiquitous in democratic societies. Does the model simply isolate one among many sufficient conditions for bureaucratic growth, a condition which may hold only in the United States?

A comparative study of western democracies offers an opportunity for providing some answers to the generality of the 
mode1. A11 other things being equal, bureaucracy should grow more rapidly in countries that more closely approximate the governmental system assumed in the mode1. - Abstracting from these cultural

6/ Of course, other things are not equal; differences in cultural backgrounds, economic structure and other factors could be important in determining the mix of government activities that are undertaken, which in turn can lead to intercountry differences in the possibility of excessive bureaucratization. More socialistic societies, for example, can be expected to have more bureaucracy simply because a greater proportion of economic activity is controlled by government.

effects, the model presented here suggests that countries in which legislators are elected at large and/or on the basis of proportional representation ought to exhibit less growth in bureaucracy, ceteris paribus, than countries in which legislators are selected from districts on the basis of vote plurality. For example Great Britain and France, with district representation, ought to exhibit the tendencies predicted by the model to a greater extent than should the Scandinavian countries, the Netherlands, Belgium, Austria and Israel, all of which use proportional representation. Moreover, within West Germany's mixed legislature, representatives elected from districts ought to behave differently than legislators who are selected on the basis of proportional representation.

The paper paints a pessimistic picture, indeed, about the 1ikely success of a "good government" movement. Not only does the model pin ultimate responsibility for the expansion of bureaucracy on legislators, it further illustrates that neither legislators, voters nor agencies may have sufficient incentives to take actions to reverse the trend. One can imagine the process continuing until members of the bureaucracy constitute the dominant political force, in which case maintaining the bureaucracy becomes an end of government rather than a means for retaining political power. The only barrier to this eventual result is that bureaucratic costs may become sufficiently large before bureaucrats attain a plurality that the gains from reform, even when multiplied by the tiny probability that a single legislator will succeed, exceed the value of a good facilitator. Perhaps the finding of Kaufman (1976) that government agencies can become sufficiently ineffective that the legislature will kill them off provides support for the latter possibility. 
REFERENCES

Buchanan, J, and G. Tullock, 1962, The Calculus of Consent (University of Michigan Press, Ann Arbor).

Burnham, W., 1974, Communication, American Political Science Review $68,207-210$.

Davis, O.A., M. Hinich and P. Ordeshoo, 1970, An Expository Development of a Mathematic1 Mode1 of the Electoral Process, American Politica1. Science Review 64, 426-448.

Downs, A., 1957, An Economic Theory of Democracy (Harper, New York).

Erikson, R.S., 1971, The Advantage of Incumbency in Congressional Elections, Polity 3, 395-405.

Ferejohn, J.A., 1977, On the Decline of Competition In Congressiona1 Elections, American Political Science Review 71, 166-176.

Fiorina, M.P., 1977, Congress -- Keystone of the Washington Estab1ishment (Yale, New Haven).

Groves, T. and J. Ledyard, 1976, Optimal Allocation of Pubific Goods: A Solution to the 'Free Rider Problem.' Discussion Paper No. 144, Center for Mathematical Studies in Economics and Management Science, Northwestern University, Evanston, I11inois.

Kaufman, H., 1976, Are Government Agentces Immorta1? (Brookings Institution, Washington, D.C.).

Mayhew, D., 1974, Congressional Elections: The Case of the Vanishing Margina1s, Po1ity 6, 295-317.
Niskanen, W., 1971, Bureaucracy and Representative Government (A1dineAtherton, Chiçago).

01son, M., 1973, Evaluating Performance in the Public Sector, in: M. Moss, ed., Conference on the Measurement of Economic and Social Performance, Studies in Income and Wealth 38 (Columbia, New York).

Tufte, E., 1973, The Relationship Between Seats and Votes in Two-Party Systems, American Political Science Review 67, 540-554.

Warner, W.L., P. VanıRiper, N. Martin, and 0. Collins, 1963, The American Federa1 Executive (Yale, New Haven).

Weber, M., 1946, Bureaucracy, In: H.H. Gerth and C. Wrifht Mi11s, eds., From Max Weber: Essays in Sociology (Oxford, New York).

Weingast, B., 1976, A Rational Choice Perspective on Congressional Norms. Social Science Working Paper No. 142, California Institute of Technology, Pasadena, California.

Wildavsky, A., 1974, The Politics of the Budgetary Process, 2d ed. (Little, Brown, Boston). 